\title{
Non-parametric analysis of seasonality in birth and multiple sclerosis risk in second generation of migrants in Kuwait
}

\author{
Saeed Akhtar ${ }^{1 *}$, Raed Alroughani ${ }^{2,3}$, Ahmad Al-Shammari ${ }^{4}$, Jarrah Al-Abkal ${ }^{5}$ and Yasser Ayad ${ }^{6}$
}

\begin{abstract}
Background: There are inconsistent reports about multiple sclerosis (MS) risk among migrants from low to high MS risk geographical regions. This study assessed the overall MS incidence and evaluated seasonality in birth and subsequent MS risk later in the life in second generation of migrants born and lived in Kuwait.

Methods: We assessed the overall and gender-specific MS risk in second generation of migrants born and lived in Kuwait between January 1, 1950 and April 30, 2013. Data on migrants' MS patients diagnosed and registered in Kuwait National MS Registry were used. Hewitt's non-parametric test was carried out to evaluate the seasonality in migrants' MS births in comparison with the second generation migrants' births in general population.

Results: During the study period, an overall risk of migrants' MS births (per 100,000 non-Kuwaiti births in general population) was 23.8 (95\% Cl: 20.8 - 27.0). Gender-specific MS risk showed that non-Kuwaiti female had statistically significant ( $p=0.003$ ) higher risk (28.6; 95\% Cl: 24.2 - 33.7) than non-Kuwaiti males (18.7; 95\% Cl: 15.1-23.0). The monthspecific distribution of migrants' MS births compared with migrants' births in general population did not differ significantly ( $x^{2}$ goodness-of-fit test statistic $\left.=9.51, p=0.575\right)$. Hewitt's non-parametric test revealed an evidence of slight but statistically non-significant $(p=0.090)$ increased tendency of migrants' MS births during September through February.

Conclusions: The proportion of migrants' MS births (per 100,000 migrants' births in general population) over the study period was 23.8 (95\% Cl: 20.8 - 27.0), which was statistically significantly higher than the previously reported Kuwaiti national MS births (16.2; 95\% Cl: 15.1-17.4) in Kuwait. Non-parametric analysis showed slight but statistically non-significant increased tendency of migrants' MS births from September through February. Knowledge of MS risk factors and how and when they act among genetically vulnerable individuals from gestation to early adulthood will help design prevention strategies.
\end{abstract}

\section{Background}

Multiple sclerosis (MS) is a highly debilitating immune mediated disorder of the central nervous system and is often progressive and fatal. MS etiology seems to be determined by environmental factors and genetic predisposition [1]. The contribution of each factor in MS etiology may vary in different geographic areas resulting into atypical spatial patterns of its incidence across the globe [2]. Hitherto known spatial pattern of MS reflects the highest prevalence, morbidity and mortality rates in the temperate zones of both northern and southern

\footnotetext{
*Correspondence: saeed.akhtar@hsc.edu.kw

'Department of Community Medicine \& Behavioural Sciences, Faculty of

Medicine, University of Kuwait, PO Box 24923, Safat 13110, Kuwait

Full list of author information is available at the end of the article
}

hemispheres and with decreasing rates in the subtropics and tropics. For instance, Europe, Canada and the northern parts of United States are high risk areas, whereas the Asia, Africa and West Indies are regarded as low risk areas [3]. So far, no specific exogenous or genetic basis for the spatial pattern has been identified, but it is speculated that some climatologic condition influences the frequency of the disease. It is unknown whether this effect is a direct on the patient or an indirect effect on the animal or plant life in his environment $[1,4]$.

Studies on migratory populations have indicated that the MS risk among those migrating from a high to a low risk area exceeds that of the population into which they have immigrated. Furthermore, those who migrate from a high-risk area to a low-risk area keep their high risk 
unless they migrate below the age of sixteen [5-7]. There are inconsistent reports regarding MS risk among immigrants from low risk areas such as Asia, East Africa and Caribbean to high MS risk areas. Additionally, as noted earlier, MS risk depends on age at the time of migration [8]. Reportedly, MS was relatively uncommon among West Indian and Asian immigrants to UK [8-10]. However, children of Asian and West Indian immigrants born in England and Wales had MS prevalence similar to that in the general population of England and Wales [11,12].

Based on Kurtzke classification, Arabian Gulf region is located in a low-risk zone for MS [13]. However, recent studies suggest a moderate-to-high MS prevalence (range: $31-55$ cases $\times 10^{-5}$ individuals) with an increase in incidence in recent years [14,15]. Arabian Gulf countries including Kuwait have a large population of migrant workers from Asian and African countries. Prior to first Gulf War in 1990, MS prevalence in Kuwait was significantly higher among non-Kuwaiti (mainly Palestinians) $\left(23.8 \times 10^{-5}\right)$ than Kuwaiti $\left(9.5 \times 10^{-5}\right)[16]$. However, the composition of population in Kuwait radically changed due to sociopolitical reasons since the first Gulf War in 1990. There was an influx of migrant workers from South and South-east Asia and other Arab countries replacing a pre-war a major expatriate group of Palestinians [15]. Furthermore, during the post- Gulf War era, the MS prevalence in Kuwait increased from $6.7 \times 10^{-5}$ in 1993 to $14.8 \times 10^{-5}$ in 2000 . Moreover, in a complete reversal of the pattern observed before 1990, this difference was more pronounced among Kuwaiti $\left(31.2 \times 10^{-5}\right)$ than non-Kuwaiti $\left(5.6 \times 10^{-5}\right)$ migrant workers. Therefore, in a geographic area with previously low MS prevalence, the local environment may be responsible for the dramatic change in MS risk [15]. Seasonal pattern in MS births has been consistent of several studies conducted in a number of regions and countries [17]. Month of birth is a surrogate for continuous environmental trait which might be present during the entire year and peak at certain period rather than being present only on month or season [1]. Previously in Kuwait, we demonstrated birth of month effect on the MS risk among the Kuwaiti born in Kuwait using parametric statistical models. However, similar relationship did not hold for non-Kuwaiti born in Kuwait [18]. This study assessed the overall MS incidence and evaluated the month of birth effect on MS risk among non-nationals born, lived and diagnosed with MS in Kuwait from January 1950 to April 2013 using non-parametric analysis of the data from Kuwait National MS Registry.

\section{Methods}

\section{Study setting}

Kuwait is a small oil-rich country with a total approximate area of $18,000 \mathrm{~km}^{2}$ and a total population of 3.5 million. Kuwait is located at north-west corner of the Arabian Gulf between latitudes $28^{\circ} 45^{\prime} \mathrm{N}$ and $30^{\circ} 05^{\prime} \mathrm{N}$ and longitudes $46^{\circ} 30^{\prime}$ and $48^{\circ} 30^{\prime}$. The state is bounded by Saudi Arabia on the south and by Iraq on the north and west. The weather is typical of the Sahara geographical region: winter is short and cool with a mean maximum temperature of $17.7^{\circ} \mathrm{C}$ and a mean minimum temperature of $7.7^{\circ} \mathrm{C}$ in January; summer is long and hot with a mean maximum temperature of $46.6^{\circ} \mathrm{C}$ in July; spring and fall are short. Kuwait has a mean annual rainfall of $79.1 \mathrm{~mm}$ and a mean daily sunshine of $8: 39 \mathrm{~h}$ [16]. Most of the population inhabits the eastern part of the country, which is close to the Arabian Gulf. It is estimated that only $8 \%$ of the Kuwait land area is inhabited [19]. Nonnationals constitute about $68 \%$ of the population and resultantly $80 \%$ of the labour force comprises migrants. The majority of migrants are male with a low educational attainment [20]. Amongst nationals the male and female literacy rates (defined as individuals aged 10 years or more and who can read and write) are $98.5 \%$ and $91.2 \%$, respectively, with a gender ratio (male/female) of 1:1.04 at birth [15]. Petroleum and petrochemical products constitute the major industry [16].

\section{Data}

A detailed description of Kuwait MS registry has been provided elsewhere $[14,18]$. Briefly, a Kuwait National MS Registry was established in October 2010 after combining the database of all major hospitals including MS clinics which together accounted for nearly $98 \%$ of the MS patients diagnosed in Kuwait. Patients who met the revised 2010 McDonald Criteria for the MS diagnosis were included in the registry [21]. Prior to the application of the revised 2010 McDonald criteria, MS diagnosis was based on the previously accepted diagnostic criteria such as Schumacher, Poser or earlier versions of McDonald criteria [22-24]. Given the stringent definitions, MS patients diagnosed according to the older diagnostic criteria, would have also satisfied the 2010 revised version of McDonald criteria and hence included in the MS registry. Data on demographics (date of birth, gender and nationality) and clinical characteristics were extracted from patients' medical records maintained at respective hospitals for inclusion in the registry. The reference population data for monthly births' by gender and nationality were obtained from the records of Public Authority for Civil lnformation, Ministry of Interior, Kuwait.

\section{Statistical analysis}

All the non-Kuwaiti MS patients diagnosed and registered between January 1, 1950 and April 30, 2013 in Kuwait National MS Registry were included. The reference group included all the non-Kuwaiti births in general population during the interval matched with that of non-Kuwaiti MS patients. The overall proportion (95\% 
Table 1 Monthly distribution of multiple sclerosis births among non-nationals in Kuwait: January 1, 1950 - April 302013

\begin{tabular}{llll}
\hline \multirow{2}{*}{ Month } & \multicolumn{2}{l}{$\begin{array}{l}\text { Multiple sclerosis births January } \\
\mathbf{1 9 5 0} \text {-April }\end{array} \mathbf{3 0 ,}, \mathbf{2 0 1 3}$} & $\begin{array}{l}\text { Total number of births } \\
\text { among non-nationals }\end{array}$ \\
\cline { 2 - 3 } & $\begin{array}{l}\text { Observed } \\
\text { MS births }\end{array}$ & $\begin{array}{l}\text { Expected } \\
\text { MS births }\end{array}$ & \\
\hline Jan & 18 & 21 & 86407 \\
Feb & 22 & 18 & 74709 \\
Mar & 17 & 19 & 81832 \\
Apr & 28 & 19 & 80336 \\
May & 15 & 20 & 82850 \\
June & 14 & 19 & 80437 \\
July & 17 & 20 & 84314 \\
Aug & 20 & 20 & 83482 \\
Sept & 20 & 20 & 83319 \\
Oct & 24 & 21 & 86844 \\
Nov & 22 & 20 & 84502 \\
Dec & 20 & 21 & 88000 \\
\hline
\end{tabular}

confidence interval (CI) of MS births of total non-Kuwaiti births in population was computed. Proportions (95\% CI) of MS births by gender were also computed using the total non-Kuwaiti births in population. Hewitt's non-parametric test was used to evaluate the seasonality in non-nationals' MS births in Kuwait and subsequent risk of MS later in the life.

\section{Ethical considerations}

We used the anonymized registry data, therefore, ethical approval of the study was neither required nor was it solicited.

\section{Results}

During the study period, non-nationals born in Kuwait had an overall risk of MS births (per $10^{5}$ non-Kuwaiti births in general population) as 23.8 (95\% CI: 20.8 - 27.0). Gender-specific risk of MS births (per $10^{5}$ non-Kuwaiti births by gender in general population) showed nonKuwaiti female had statistically significant $(p=0.003)$ increased risk (28.6; 95\% CI: 24.2 - 33.7) than non-Kuwaiti males (18.7; 95\% CI: 15.1-23.0) (Table 1). Non-Kuwaiti females born and lived in Kuwait were 1.5 times more likely to have been diagnosed with MS than non-Kuwait males born and lived in Kuwait (Relative risk $=1.5$; 95\% CI: 1.2 - 2.0). The month-specific distribution of non-Kuwaiti MS births compared with non-Kuwaiti births in general population did not differ significantly ( $\chi^{2}$ goodness-of-fit test statistic $=9.51, p=0.575$ ). Of rank-sums for successive 6-month segments based on the Hewitt's non-parametric test, from September through-February period showed an evidence of slight but statistically non-significant ( $p=0.090)$ increased tendency of non-Kuwaiti MS births (Tables 2 and 3).

\section{Discussion}

In this evaluation, the proportion of migrants MS births over the study period was statistically significantly higher than previously reported Kuwaiti MS births [18]. Nonparametric analysis revealed slight but statistically nonsignificant increased tendency of migrants' MS births from September through February. There are inconsistent reports on the question of MS risk in migrant populations. The MS risk among migrants seems to be dependent not only on a sufficiency of people who change their residence from one risk area to another but also on ages at immigration and their length of stay (exposure period) in the new land. Additionally, this relationship of geography

Table 2 Month-specific total number of non-national births, multiple sclerosis births, estimates of expected relative incidence, observed relative incidence (ORI) and ORI ranks: Kuwait, January 1, 1950 - April 30, 2013

\begin{tabular}{|c|c|c|c|c|c|}
\hline Months & $\begin{array}{l}\text { Non-national births } \\
(\mathrm{n}=997269)\end{array}$ & $\begin{array}{l}\text { MS births } \\
(n=237)\end{array}$ & $\begin{array}{l}\text { Expected relative } \\
\text { incidence }\left(\times 10^{3}\right)\end{array}$ & $\begin{array}{l}\text { Observed relative } \\
\text { incidence }\left(\times 10^{3}\right)\end{array}$ & ORI rank \\
\hline $\operatorname{Jan}$ & 86425 & 18 & 0.020184 & 0.017689 & 5 \\
\hline Feb & 74731 & 22 & 0.018231 & 0.022583 & 10 \\
\hline Mar & 81849 & 17 & 0.020184 & 0.01764 & 4 \\
\hline Apr & 80364 & 28 & 0.019533 & 0.028637 & 12 \\
\hline May & 82865 & 15 & 0.020184 & 0.015374 & 2 \\
\hline June & 80451 & 14 & 0.019533 & 0.014303 & 1 \\
\hline July & 84331 & 17 & 0.020184 & 0.017121 & 3 \\
\hline Aug & 83502 & 20 & 0.020184 & 0.020342 & 8 \\
\hline Sept & 83339 & 20 & 0.019533 & 0.019725 & 7 \\
\hline Oct & 86868 & 24 & 0.020184 & 0.023465 & 11 \\
\hline Nov & 84524 & 22 & 0.019533 & 0.021393 & 9 \\
\hline Dec & 88020 & 20 & 0.020184 & 0.019298 & 6 \\
\hline
\end{tabular}


Table 3 Hewitt's non-parametric analysis of MS births among non-nationals in Kuwait: January 1, 1950 - April 30, 2007

\begin{tabular}{lll}
\hline Hewitt's test for six month segments & Rank-sum & $\boldsymbol{P}$-value \\
\hline Jan-Jun & 34 & $>0.25$ \\
Feb-Jul & 32 & $>0.25$ \\
Mar-Aug & 30 & $>0.25$ \\
Apr-Sep & 33 & $>0.25$ \\
May-Oct & 32 & $>0.25$ \\
Jun-Nov & 39 & $>0.25$ \\
Jul-Dec & 44 & 0.242 \\
Aug-Jan & 46 & 0.155 \\
Sep-Feb & 48 & 0.090 \\
Oct-Mar & 45 & 0.197 \\
Nov-Apr & 46 & 0.155 \\
Dec-May & 39 & $>0.25$ \\
\hline
\end{tabular}

and MS risk is further confounded by predilection for MS regardless of region [25,26]. There is evidence from mortality data that moving from low-risk to high-risk MS regions does increase the risk of dying from MS [27]. Unpublished data also showed an increased MS risk among southern-born US-veterans who moved to North of US and Vietnamese who moved to France, though these results were considered non-confirmatory [27]. UK born-children of West Indian immigrants had the same magnitude of probable MS incidence and prevalence as was among Irish population in Northern Ireland. This finding indicated that although genetic factors play role but there is strong evidence that the cause of disease is mainly environmental and therefore preventable [28].

In line with earlier studies investigating the genetic and spatial epidemiology of this complex disease, more recent studies have highlighted how MS arises from a combination of genetic susceptibility and environmental exposures acting from gestation to early adulthood. For example, in a recent meta-analysis it has been argued that latitude-dependent month of birth effect on MS risk is likely due to ultraviolet light exposure and maternal vitamin D level [29]. Conversely, Fiddes et al. reasoned-out that confounding underlies this apparent association of month of birth and MS risk. The authors claimed that using national birth statistics as controls may generate false-positive association of MS with month of birth [30]. However, a limitation of aforementioned study is that the researchers did not analyze the original studies that highlighted the month of birth effect in MS [30]. Instead, they performed a separate study on national un-weighted births statistics, thereby showing potential sources of bias in such studies [30,31]. Nevertheless, in search of causal relationships, season of birth, maternal Vitamin D deficiency, Epstein Barr virus infection, and smoking behaviour are strongly implicated and seem to influence genetic predisposition to MS. Additionally, these factors appear to act synergistically and the risk of MS in individuals exposed to more than one factor combines multiplicatively $[1,4,31,32]$. Further research is needed to fully understand the environmental risk factors for MS and in this regard longitudinal studies of at-risk populations should be considered [32]. Knowledge of such risk factors may help design preventive strategies to minimize MS risk.

\section{Conclusions}

The proportion of migrants' MS births (per $10^{5}$ nonnational births in general population) over the study period was 23.8 (95\% CI: 20.8 - 27.0), which was statistically significantly higher than previously reported Kuwaiti MS births (16.2; 95\% CI: 15.1 - 17.4) in Kuwait. Nonparametric analysis revealed slight but statistically nonsignificant increased tendency of migrants' MS births from September through February. Knowledge of MS risk factors and how and when they act among genetically vulnerable individuals from gestation to early adulthood will help design prevention strategies.

\section{Competing interests \\ The authors declare that they have no competing interests.}

\section{Authors' contributions}

SA conceived the research idea and design of the study, analyzed and interpreted the data, drafted the manuscript, critically revised the manuscript, RA helped in setting up Kuwait Multiple Sclerosis Registry, provided administrative and technical support, supervised and facilitated data acquisition, interpreted the results, critically reviewed the draft. AA, JA, YA helped in data acquisition and reviewed the draft. All authors read and approved the final manuscript.

\section{Acknowledgements}

We thank administrative staff of Public Authority of Civil Information, Ministry of Interior and National MS Registry, Kuwait for providing access to required data.

Funding

This research received no specific grant from any funding agency.

\section{Author details}

${ }^{1}$ Department of Community Medicine \& Behavioural Sciences, Faculty of Medicine, University of Kuwait, PO Box 24923, Safat 13110, Kuwait. Division of Neurology, Department of Medicine, Amiri Hospital, Arabian Gulf Street, Kuwait City 13041, Kuwait. ${ }^{3}$ Neurology Clinic, Dasman Diabetes Institute, P.O. Box 1180, Dasman 15462, Kuwait. ${ }^{4}$ Al-Adan Hospital, PO Box 288, Sabah Al Salem 44403, Kuwait. ${ }^{5}$ Department of Surgery, Farwaniya Hospital, PO Box 33978, Alrawdha 7346, Kuwait. 'Department of Neurology, Ibn Sina Hospital, Sabah Medical Area, Safat, PO Box 13115, Kuwait.

Received: 22 April 2014 Accepted: 19 August 2014

Published: 26 August 2014

\section{References}

1. Disanto G, Morahan JM, Ramagopalan SV: Multiple sclerosis: risk factors and their interactions. CNS Neurol Disord Drug Targets 2012, 11(5):545-555.

2. McAlpine D, Lumsden CE, Acheson ED: Multiple Sclerosis-A Reappraisal. London: Churchill Livingstone; 1971.

3. Spillane JD: Tropical Neurology. London: Oxford University Press; 1973.

4. van der Mei IA, Simpson S Jr, Stankovich J, Taylor BV: Individual and joint action of environmental factors and risk of MS. Neurol Clin 2011, 29(2):233-255 
5. Dean $G$, Kurtzke JF: On the risk of multiple sclerosis according to age at immigration to South Africa. Br Med J 1971, 3:5.

6. Dean G: Annual incidence, prevalence and mortality of multiple sclerosis in white South African-born and in white immigrants to South Africa. Br Med J 1967, ii:724-730.

7. Leibowitz U: Multiple sclerosis: Clues to its cause. American Elsevier Pub. Co: Amsterdam, North Holland; 1973.

8. Jain S, Maheshwari MC: Multiple sclerosis: Indian experience in the last 30 years. Neuroepidemiology 1985, 4:12.

9. Dean G, McLoughlin H, Brady $\mathrm{R}$, Adelstein AM, Tallett-Williams J: Multiple sclerosis among immigrants in Greater London. Br Med J 1976, 1:861-864.

10. Dean GBR, McLoughlin H, Elian M, Adelstein AM: Motor neurone disease and multiple sclerosis among immigrants to Britain. Br J Prev Soc Med 1977, 31:141-147.

11. Elian M, Dean G: Motor neuron disease and multiple sclerosis among immigrants to England from the Indian subcontinent, the Caribbean and East and West Africa. J Neurol Neurosurg Psychiatry 1993, 56:4.

12. Elian M, Nightingale S, Dean G: Multiple sclerosis among United Kingdom-born children of immigrants from the Indian subcontinent, Africa, and the West Indies. J Neurol Neurosurg Psychiatry 1990, 53:6.

13. Kurtzke JF: A reassessment of the distribution of multiple sclerosis. Acta Neurol Scand 1975, 51(2):137-157.

14. Alroughani R, Ahmed S, Behbahani R, Khan R, Thussu A, Alexander K, Ashkanani A, Nagarajan V, Al-Hashel J: Increasing prevalence and incidence rates of multiple sclerosis in Kuwait. Mult Scler 2014, 20(5):543-547.

15. Alshubaili AF, Alramzy K, Ayyad YM, Gerish Y: Epidemiology of multiple sclerosis in Kuwait: new trends in incidence and prevalence. Eur Neurol 2005, 53(3):125-131.

16. Khogali M, Poser CM, Shakir R, Hussain J, Behbahani K, Chadha G: Epidemiology of multiple sclerosis in Arabs in Kuwait: a comparative study between Kuwaitis and Palestinians. J Neurol Sci 1990, 100(1-2):137-141.

17. Torkildsen O, Grytten N, Aarseth J, Myhr KM, Kampman MT: Month of birth as a risk factor for multiple sclerosis: an update. Acta Neurol Scand Supp/ 2012, 195:58-62.

18. Akhtar S, Alroughani R, Al-Shammari A, Al-Abkal J, Ayad Y: Month of birth and risk of multiple sclerosis in Kuwait: A population-based registry study. Mult Scler 2014, [Epub ahead of print]. doi:10.1177/1352458514541578.

19. Ziyab AH, Akhtar S: Incidence and trend of road traffic injuries and related deaths in Kuwait: 2000-2009. Injury 2012, 43(12):2018-2022.

20. Akhtar S, Mohammad HG: Spectral analysis of HIV seropositivity among migrant workers entering Kuwait. BMC Infect Dis 2008, 8:37.

21. Polman CH, Reingold SC, Banwell B, Clanet M, Cohen JA, Filippi M, Fujihara K, Havrdova E, Hutchinson M, Kappos L, Lublin FD, Montalban X, O'Connor P, Sandberg-Wollheim M, Thompson AJ, Waubant $E$, Weinshenker $B$ Wolinsky JS: Diagnostic criteria for multiple sclerosis: 2010 revisions to the McDonald criteria. Ann Neurol 2011, 69(2):292-302

22. McDonald WI, Compston A, Edan G, Goodkin D, Hartung HP, Lublin FD, McFarland HF, Paty DW, Polman CH, Reingold SC, Sandberg-Wollheim M, Sibley W, Thompson A, van den Noort S, Weinshenker BY, Wolinsky JS: Recommended diagnostic criteria for multiple sclerosis: guidelines from the International Panel on the diagnosis of multiple sclerosis. Ann Neurol 2001, 50(1):121-127.

23. Poser CM, Paty DW, Scheinberg L, McDonald WI, Davis FA, Ebers GC, Johnson KP, Sibley WA, Silberberg DH, Tourtellotte WW: New diagnostic criteria for multiple sclerosis: guidelines for research protocols. Ann Neurol 1983, 13(3):227-231.

24. Schumacker GA, Beebe G, Kibler RF, Kibler RF, Kurland LT, Kurtzke JF, MCdowell F, Nagler B, Sibley WA, Tourtellotte WW, Willmon TL: Problems of experimental trials of therapy in multiple sclerosis: report by the panel on the evaluation of experimental trials of therapy in multiple sclerosis. Ann N Y Acad Sci 1965, 122:552-568.

25. Dean $G$, Kurtzke JF: On the risk of multiple sclerosis according to age at immigration to South Africa. Br Med J 1971, 3(5777):725-729.

26. Kurtzke JF: Multiple sclerosis among immigrants. Br Med J 1976, 1(6024):1527-1528.

27. Kurtzke JF, Kurland LT, Goldberg ID: Mortality and migration in multiple sclerosis. Neurology 1971, 21(12):1186-1197.

28. Elian M, Dean G: Multiple sclerosis among the United Kingdom-born children of immigrants from the West Indies. J Neurol Neurosurg Psychiatry 1987, 50(3):327-332
29. Dobson R, Giovannoni G, Ramagopalan S: The month of birth effect in multiple sclerosis: systematic review, meta-analysis and effect of latitude. J Neurol Neurosurg Psychiatry 2013, 84(4):427-432.

30. Fiddes B, Wason J, Kemppinen A, Ban M, Compston A, Sawcer S: Confounding underlies the apparent month of birth effect in multiple sclerosis. Ann Neurol 2013, 73(6):714-720.

31. Hintzen R: Multiple sclerosis: month of birth effect in MS-fact or artefact? Nat Rev Neurol 2013, 9(9):489-490.

32. Disanto G, Meier U, Giovannoni G, Ramagopalan SV: Vitamin D: a link between Epstein-Barr virus and multiple sclerosis development? Expert Rev Neurother 2011, 11(9):1221-1224.

doi:10.1186/s12883-014-0170-7

Cite this article as: Akhtar et al:: Non-parametric analysis of seasonality in birth and multiple sclerosis risk in second generation of migrants in Kuwait. BMC Neurology 2014 14:170.

\section{Submit your next manuscript to BioMed Central and take full advantage of:}

- Convenient online submission

- Thorough peer review

- No space constraints or color figure charges

- Immediate publication on acceptance

- Inclusion in PubMed, CAS, Scopus and Google Scholar

- Research which is freely available for redistribution 